\title{
Clinical and social outcomes of adolescent self harm: population based birth cohort study
}

\author{
(C) (1) OPEN ACCESS
}

\author{
Becky Mars research associate in epidemiology ${ }^{1}$, Jon Heron senior research fellow ${ }^{1}$, Catherine \\ Crane senior postdoctoral research psychologist ${ }^{2}$, Keith Hawton professor of psychiatry ${ }^{3}$, Glyn \\ Lewis professor of psychiatric epidemiology ${ }^{4}$, John Macleod professor in clinical epidemiology and \\ primary care ${ }^{1}$, Kate Tilling professor of medical statistics ${ }^{1}$, David Gunnell professor of epidemiology ${ }^{1}$ \\ ${ }^{1}$ School of Social and Community Medicine, University of Bristol, Oakfield House, Bristol BS8 2BN, UK; ${ }^{2}$ Department of Psychiatry, University of \\ Oxford, Warneford Hospital, Oxford, UK; ${ }^{3}$ Centre for Suicide Research, Department of Psychiatry, University of Oxford, Warneford Hospital, Oxford, \\ UK: ${ }^{4}$ Mental Health Sciences Unit, University College London, London, UK
}

\begin{abstract}
Objectives To investigate the mental health, substance use, educational, and occupational outcomes of adolescents who self harm in a general population sample, and to examine whether these outcomes differ according to self reported suicidal intent.

Design Population based birth cohort study.

Setting Avon Longitudinal Study of Parents and Children (ALSPAC), a UK birth cohort of children born in 1991-92.

Participants Data on lifetime history of self harm with and without suicidal intent were available for 4799 respondents who completed a detailed self harm questionnaire at age 16 years. Multiple imputation was used to account for missing data.

Main outcome measures Mental health problems (depression and anxiety disorder), assessed using the clinical interview schedule-revised at age 18 years, self reported substance use (alcohol, cannabis, cigarette smoking, and illicit drugs) at age 18 years, educational attainment at age 16 and 19 years, occupational outcomes at age 19 years, and self harm at age 21 years.

Results Participants who self harmed with and without suicidal intent at age 16 years were at increased risk of developing mental health problems, future self harm, and problem substance misuse, with stronger associations for suicidal self harm than for non-suicidal self harm. For example, in models adjusted for confounders the odds ratio for depression at age 18 years was 2.21 (95\% confidence interval 1.55 to $3.15)$ in participants who had self harmed without suicidal intent at age 16 years and 3.94 (2.67 to 5.83 ) in those who had self harmed with suicidal intent. Suicidal self harm, but not self harm without suicidal intent, was also associated with poorer educational and employment outcomes.
\end{abstract}

Conclusions Adolescents who self harm seem to be vulnerable to a range of adverse outcomes in early adulthood. Risks were generally stronger in those who had self harmed with suicidal intent, but outcomes were also poor among those who had self harmed without suicidal intent. These findings emphasise the need for early identification and treatment of adolescents who self harm.

\section{Introduction}

Self harm in adolescents is an important public health concern, with community studies from around the world reporting a lifetime risk of $13-18 \% .{ }^{1-5}$ Despite this high prevalence, little is known about the longer term relevance of self harm in adolescents for outcomes in early adulthood. Existing follow-up studies have typically been conducted in small clinical samples ${ }^{6-9}$; however, clinical presentation occurs in less than $20 \%$ of adolescents who self harm in the community. ${ }^{23}$

In one of the few longitudinal population studies to examine the course of self harm, Moran et $\mathrm{al}^{10}$ found that risk declined during late adolescence, with most adolescents who self harmed reporting no further acts in adulthood. Other longitudinal studies have focused on suicidal self harm (suicide attempts) in adolescence and report associations with a range of adverse outcomes in adulthood, including an increased risk of psychiatric disorder, substance misuse, and future self harm. ${ }^{11}{ }^{12}$ However, suicide attempts comprise a relatively small proportion of self harm acts, and the longer term outcomes associated with non-suicidal self harm are not known.

The extent to which self harm with and without suicidal intent represent distinct concepts or more or less extreme versions of the same behaviour is a source of debate. ${ }^{13-17}$ Although 
researchers have begun to investigate whether there are differences in cause between these behaviours, ${ }^{18-20}$ we are not aware of any studies that have examined whether there are differences in outcomes, other than for repetition of self harm.

In a community sample we investigated the outcomes in early adulthood of self harm with and without suicidal intent in adolescence. We also examined whether there are differences in outcomes among adolescents who self harmed with and without suicidal intent.

\section{Methods}

\section{Sample}

The Avon Longitudinal Study of Parents and Children (ALSPAC) is an ongoing population based birth cohort study examining influences on health and development across the life course. The core enrolled sample consists of 14541 pregnant women resident in the former county of Avon in south west England (United Kingdom) with expected delivery dates between 1 April 1991 and 31 December $1992 .{ }^{21}$ Of the 14062 live births, 13798 were singletons or first born of twins, and were alive at 1 year of age. Participants have been followed up regularly since recruitment through questionnaires and attendance at research clinics. Information about ALSPAC is available on the study website (www.bristol.ac.uk/alspac), which includes details of all available data through a fully searchable data dictionary (www.bris.ac.uk/alspac/researchers/data-access/ data-dictionary). Written informed consent was obtained from participants after the procedures had been fully explained.

We examined mental health and substance use outcomes at age 18 years, educational, and occupational outcomes at age 16 and 19 years, and self harm at age 21 years among 4799 participants who completed a detailed self report questionnaire on self harm at age 16 years: mean age 16 years and 8 months (SD 3 months). The postal questionnaire was sent to 9383 participants, of whom $4855(51.7 \%)$ returned it and 4810 completed the self harm items. Data on lifetime suicidal intent accompanying self harm was missing for 11 respondents (figure $\Downarrow$ ). Characteristics of the subsample that responded to the self harm questionnaire have been described in detail elsewhere. ${ }^{2}$ Those who returned the questionnaire were more likely than those who did not to be female and white and to have lower parity (assessed during pregnancy), a mother with higher education (assessed during pregnancy), a higher household income, and a higher parental social class (assessed during pregnancy), and less likely to have experienced over-crowding (assessed during pregnancy) (see supplementary tables $1 \mathrm{a}$ and $\mathrm{b}$ ).

\section{Exposure measure \\ Self harm}

The self report questions used to assess lifetime history of self harm at age 16 years were based on those used in the Child and Adolescent Self harm in Europe Study. ${ }^{4}$ We classified participants as having a history of self harm who responded positively to the item "have you ever hurt yourself on purpose in any way (for example, by taking an overdose of pills or by cutting yourself)?" Two additional questions were used to identify those who had self harmed with suicidal intent; we classified participants as such if they selected "I wanted to die" as a response option to the question "Do any of the following reasons help to explain why you hurt yourself on that (the most recent) occasion?" or they responded positively to the question "On any of the occasions when you have hurt yourself on purpose, have you ever seriously wanted to kill yourself?" We refer to those who self harmed with suicidal intent at some point during their lifetime as having "harmed with suicidal intent" but recognise that many individuals in this group will have also engaged in non-suicidal self harm. ${ }^{22-24}$

Establishing suicidal intent accompanying an episode of self harm is problematic, particularly when assessed retrospectively, as reports can be influenced by current mood state and may change over time. In line with previous research, ${ }^{15}$ we classified self harm behaviours in which there was any evidence of self reported intent to die as suicidal self harm.

\section{Outcome measures}

\section{Mental health and future episodes of self harm}

Participants were assessed for depressive disorder and anxiety disorder (generalised anxiety disorder, panic disorder, phobia, social anxiety disorder) in the research clinic at age 18 years (mean age 17 years and 9 months (SD 4 months) using the computerised version of the clinical interview schedule-revised. ${ }^{25}$ This derives diagnosis according to criteria from the international classification of diseases, 10th revision. Agreement between the self administered computerised version and the interviewer administered versions of the clinical interview schedule-revised is close. ${ }^{26-28}$ Sixty nine per cent of those with information on self harm with and without suicidal intent at age 16 years attended the clinic at age 18 years $(n=3313 / 4799)$. We excluded from the analysis the 114 participants who completed the clinical interview schedule-revised less than six months after the self harm questionnaire at age 16 years.

Self harm in the past year was assessed through self report questionnaire sent to participants at age 21 years: mean age 20 years 11 months (SD 6 months). We assessed the lifetime history of self harm with the same item used in the previous questionnaire assessment at age 16 years "have you ever hurt yourself on purpose in any way (for example, by taking an overdose of pills or by cutting yourself)?" Participants who responded positively were then asked a further question about when they last harmed themselves (response options: In the last week/more than a week ago, but in the last year/more than a year ago). We dichotomised this response to create a binary indicator of self harm in the past year. Participants were not asked about suicidal intent during the past year. Sixty five per cent of those with information on self harm with and without suicidal intent at age 16 years returned the questionnaire at age 21 years $(n=3128 / 4799)$.

In secondary analyses we examined associations between self harm with and without suicidal intent at age 16 years and future hospital admissions for self harm (between the time of questionnaire completion and 31 March 2012). This analysis was conducted in a subset of the sample $(n=2363)$ who consented to data linkage with the hospital episode statistics database. $^{29}$

\section{Substance use}

We also collected information on substance use at age 18 years through self administered computer assisted interviews and included measures of harmful drinking, problem cannabis use, regular smoking, and illicit drug use. We used the 10 item alcohol use disorders identification test to assess harmful drinking. ${ }^{30}$ A cut-off of 16 or more was used to indicate harmful use. ${ }^{31}$ Problem cannabis use was measured using the six item cannabis abuse screen test, ${ }^{32}$ which assesses cannabis consumption in the previous 12 months and focuses on difficulties controlling use and associated health and social impairment. All items are answered on a 5 point scale ( 0 never, 
1 rarely, 2 from time to time, 3 fairly often, and 4 very often). A response of fairly often or very often to any of the six items was used to indicate problem cannabis use. ${ }^{33} \mathrm{We}$ derived information on smoking using a series of questions. Participants who responded positively to the questions "having ever smoked" and "having smoked in the past 30 days" were asked to indicate whether they smoked weekly. Response to this item was used as a binary indicator of regular smoking. We classified participants as having used illicit drugs other than cannabis if they indicated they had used any of the following substances over the past 12 months: cocaine, amphetamines, inhalants, sedatives, hallucinogens, or opioids.

\section{Educational and occupational outcomes}

Educational attainment or achievement was assessed through the general certificate of secondary education (GCSE) and advanced level (A level) qualifications. GCSEs are qualifications usually obtained at the end of compulsory schooling in Great Britain, at age 16 years, and are graded from $A^{*}-\mathrm{G}$. A levels are typically taken at age 18 years, after compulsory school examinations. A minimum of three A levels is usually required for university entrance. In the United States these qualifications are loosely comparable to a general high school achievement test (GCSE) and a college entrance examination, such as the scholastic achievement test (A level). We obtained GCSE results from the national pupil database key stage 4 dataset, recording pupil census and assessment data for all pupils in English government maintained schools. ${ }^{21}$ We dichotomised participants according to whether they obtained five or more GCSE (or equivalent) qualifications at grades $\mathrm{A}{ }^{*}-\mathrm{C}$; a nationally recognised threshold of attainment. Since we assessed the lifetime history of self harm at age 16 years and the age of onset was not known, it is possible that GCSE examinations may have preceded or occurred concurrently with self harm at baseline for some participants.

We assessed A level results through self report questionnaire. The mean age of respondents was 18 years and 8 months; for simplicity we refer to this as age 19 years. Participants were classified according to whether or not they had achieved three or more A level qualifications. Participants were also asked about current enrolment in education or training and current employment status. We combined responses to these two items to identify those not in education, employment, or training (NEET). In line with the definition used by the Office for National Statistics, ${ }^{34}$ participants who were not in full time or part time education or in training were classified as NEET if they were unemployed or otherwise economically inactive (not in employment but not actively seeking work). Fifty six per cent of those with information on self harm with and without suicidal intent at age 16 years returned the questionnaire at age 19 years $(\mathrm{n}=2707 / 4799)$.

\section{Possible confounders}

In additional analyses we controlled for the possible confounding effects of socioeconomic position and previous symptoms of depression. Socioeconomic position was assessed through maternal questionnaire in pregnancy and included highest maternal educational attainment, we used four categories: university degree; A level or advanced level (which are after compulsory school qualifications); O level, or ordinary level (which are academic qualifications taken at the end of compulsory schooling. O levels are now defunct in the United Kingdom and have been replaced by GCSE examinations); and less than $\mathrm{O}$ level, which includes any other qualifications of a lower academic standard or no qualifications at all), and social class (professional or managerial or other occupations. We used the highest of maternal or paternal social class). We assessed symptoms of depression at age 13 years using the short mood and feelings questionnaire. ${ }^{35}$ Owing to the well established association of IQ with both self harm and school performance, we additionally controlled for child IQ when investigating educational and occupational outcomes. We assessed child IQ at age eight years using the Wechsler intelligence test for children, third edition. ${ }^{36}$

\section{Statistical analysis}

Logistic regression was used to examine associations between self harm with and without suicidal intent at age 16 years and each of the mental health, substance use, educational, and occupational outcomes at age 18-21 years. All analyses controlled for participants' sex. Additional multivariable analyses controlled for socioeconomic position and the number of previous depression symptoms. To obtain a direct comparison between self harm with suicidal intent and self harm without suicidal intent, we re-estimated each model with an alternative reference group to provide this additional information. There was little evidence to suggest that associations differed between males and females (interaction $P$ values ranged from 0.12 to 0.95), therefore our analyses are based on the sexes combined. All analyses were conducted using Stata version 12.

\section{Missing data}

Our primary analyses were conducted on an imputed dataset based on those with complete data on self harm with and without suicidal intent at 16 years $(n=4799)$. The number of respondents with complete data (on outcome and all covariates) ranged from 1743 (for not achieving $\geq 3$ A levels) to 2777 (for not achieving $\geq 5$ GCSE or equivalent $A *$-C grades). To create multiple copies of datasets in which missing values were replaced by imputed values sampled from their predictive distribution, we conducted multiple imputation by chained equations using the ice command in Stata. ${ }^{37}$ This method assumes that data are missing at random, whereby any systematic differences between the missing and the observed values can be explained by differences in observed data. ${ }^{38}$ Overall, we generated 100 imputed datasets for each outcome of interest. In the imputation models we included all variables used in the analysis along with several additional auxiliary variables. These included variables found to be predictive of missingness (see supplementary tables 1a and b), indicators of socioeconomic adversity, personal characteristics, and maternal psychopathology as well as strong correlates of the outcome variables, such as similar measures from the domains of mental health and substance use collected earlier in the study. Although we cannot say with absolute certainty that the data were missing at random, we feel justified in making the missing at random assumption in this instance, given the wealth of auxiliary information available. Monte Carlo errors are available on request.

\section{Onset models}

A secondary analysis was performed to examine the potential impact of pre-existing problems. We refer to these as onset models as our interest is in the effect of lifetime self harm among those not currently exhibiting symptoms of each outcome measure. For example, an observed association between self harm and later alcohol problems at age 18 years might be due, in whole or in part, to increased alcohol use at baseline.

Consequently, for each outcome in turn, we flagged those who had shown evidence of pre-existing problems and examined the 
associations between self harm and the outcome among the problem-free participants. The indicators of pre-existing problems were specific to each outcome and utilised any available data collected during the period from age 11 to 16 years. More information is provided in the footnote to table 3.

Although the effect of self harm among those without alcohol related problems may be estimated simply by excluding those with pre-existing harmful alcohol use, extending this approach to incorporate multiple imputed data is not trivial. Therefore utilising a series of appropriately parameterised interaction models we obtained the same estimates. Here we incorporated our flags for pre-existing problems as a series of moderator variables both within the imputation step and within the analysis that followed. By building interaction terms into the imputation routine the effect of self harm on a particular outcome is allowed to differ between cases with and without pre-existing problems. In addition, the ability to calculate the estimates of interest without excluding cases meant that the model estimated within each imputed dataset was based on the same sample size, irrespective of the flagged sample that would be expected to vary in magnitude owing to missing data in these measures. Given the number of interaction terms required, we derived a separate imputation model for each outcome in turn.

\section{Results}

In total, $19 \%$ of the sample reported a lifetime history of self harm at age 16 years $(n=894 / 4799)$; these participants account for $24 \%$ of those who were not in education, employment, or training (NEET) at age 19 years, $40 \%$ of those with depressive and anxiety disorders, and over $35 \%$ of those with problem substance use at age 18 years. The prevalence of good outcomes (no mental health or substance use problems and not NEET) among participants who had self harmed was half when compared with those without a history of self harm $(28 \% \mathrm{v}$ $59 \%$ ), highlighting that these adolescents are a high risk group.

Table $1 \Downarrow$ provides descriptive information for each outcome according to self harm at age 16 years. For mental health outcomes, future self harm, and substance use there was evidence of a dose-response relation with lifetime self harm at age 16 years; the prevalence of each outcome was highest among participants who had self harmed with suicidal intent, lowest among those with no history of self harm, and approximately midway between the two for those who had self harmed without suicidal intent. Poorer educational achievement was also most prevalent among those with suicidal self harm, although educational outcomes seem to have been slightly better among those with non-suicidal self harm than among those who had never self harmed. The prevalence of NEET was similar among those with no self harm and with non-suicidal self harm, but higher among those with suicidal self harm.

Table $2 \Downarrow$ shows the associations of self harm with and without suicidal intent at age 16 years with outcomes at age 18-21 years. The omnibus $P$ values test for a difference in odds across the three levels of self harm. For each outcome in the table, the first two rows of odds ratios show associations between the outcome variable and history of self harm both without and with suicidal intent at age 16 years; the reference group for these odds ratios are adolescents who have never self harmed. The third row of odds ratios show differences in the outcome between those who self harmed with and without suicidal intent; the reference group for these odds ratios are adolescents with non-suicidal self harm. In this row, odds ratios greater than 1 indicate that a particular outcome is more strongly associated with suicidal self harm than with non-suicidal self harm; odds ratios less than 1.0 indicate the opposite.

\section{Mental health outcomes and future self harm}

Self harm with and without suicidal intent at age 16 years were strongly associated with later depression and anxiety disorder at age 18 years and with future episodes of self harm at age 21 years (table 2). Compared with those who had never self harmed, non-suicidal self harm was associated with a more than twofold increase in the odds of depression and anxiety disorder, and suicidal self harm with a fivefold increase in odds. Associations were particularly strong for future episodes of self harm (non-suicidal self harm odds ratio $4.60,95 \%$ confidence interval 3.23 to 6.54 and suicidal self harm 12.6, 8.91 to 17.8). All outcomes were more strongly associated with suicidal self harm than with non-suicidal self harm (odds ratio range 2.04-2.74). After adjustment for socioeconomic position and previous symptoms of depression at age 13 years, there was little attenuation in results.

Of the 2363 participants linked to hospital records, 18 (0.8\%) had at least one recorded hospital admission for self harm identified in the hospital episode statistics database: no self harm $n=11(0.6 \%)$, non-suicidal self harm $n=1(0.4 \%)$, and suicidal self harm $n=6(4.4 \%)$. In univariable analyses, an association with hospital admission was found only for suicidal self harm (odds ratio 7.99, 95\% confidence interval 2.91 to 21.9), with little evidence of an association for non-suicidal self harm $(0.63,0.08$ to 4.88$)$. However, these findings need to be interpreted with caution given the small number of participants with a hospital admission in the analysis.

\section{Substance use outcomes}

Self harm with and without suicidal intent at age 16 years were associated with later substance use at 18 years (table 2). Harmful alcohol use and illicit drug use outcomes were more common in those with suicidal self harm than with non-suicidal self harm; however, strong evidence for a difference between the self harm groups was found only for problem cannabis use (odds ratio $2.32,95 \%$ confidence interval 1.31 to 4.10 ) and smoking regularly $(1.42,1.00$ to 2.00$)$. After adjustment for socioeconomic position and symptoms of depression at age 13 years, there was little attenuation in results.

\section{Educational and occupational outcomes}

For GCSE and A level qualifications, there was a difference in the pattern of association across the self harm groups (table 2). In univariable analysis, the odds of not achieving five or more GCSEs or equivalent $\mathrm{A}^{*}$-C grades and not achieving three or more A levels was increased among those with suicidal self harm (odds ratio for GCSE 2.24, 95\% confidence interval 1.70 to 2.95 and for A level 1.53, 1.12 to 2.09), but reduced among those with non-suicidal self harm (GCSE $0.83,0.62$ to 1.11 and A level $0.85,0.67$ to 1.08 ), although findings for non-suicidal self harm did not reach conventional levels of significance. After adjustment for socioeconomic position, symptoms of depression, and IQ, strong evidence remained only for suicidal self harm and GCSE qualifications. Self harm with suicidal intent was also associated with an increased risk of being NEET at age 19 years (adjusted odds ratio 1.96, 95\% confidence interval 1.16 to 3.31 ). 


\section{Secondary analysis: onset models examining effect of previous problems}

Table $3 \Downarrow$ presents the onset models, showing the association of self harm with and without suicidal intent with each outcome among those without evidence of pre-existing problems. Overall, there was little evidence to suggest that the previous strong associations could be explained by pre-existing conditions that may confer an increased risk of self harm at age 16 years, as effect estimates were generally consistent with those from the previous models. However, for depression and anxiety disorder, associations with suicidal self harm were attenuated, resulting in an overall reduction in the difference in risk between the two self harm groups. Suicide attempts are strongly associated with psychiatric disorder, ${ }^{39}{ }^{40}$ and it is notable that more than three quarters $(77 \%)$ of participants with suicidal self harm were found to have a history of probable depression. The small number of respondents with suicidal self harm retained in the analyses resulted in wide confidence intervals, and we cannot conclude from this that the variable estimates have changed. These findings therefore need to be interpreted with caution.

\section{Comparison of complete case and imputed data}

Supplementary tables 2 and 3 present the results of the complete case analysis. Findings were generally consistent with those from the imputed models. Supplementary table 4 provides unadjusted models using the maximum amount of data available.

\section{Discussion}

In our analyses of the Avon Longitudinal Study of Parents and Children (ALSPAC) cohort, adolescents who had self harmed by age 16 years had an increased risk of mental health problems, future self harm episodes, and problem substance use in early adulthood compared with adolescents who had not self harmed. Those who self harmed with suicidal intent at some point were also at increased risk of poorer educational and occupational outcomes. Although associations were generally stronger for suicidal self harm than for non-suicidal self harm, those who had self harmed without suicidal intent were also at increased risk of adverse outcomes. Findings from the onset models indicate that associations were not entirely explained by pre-existing psychopathology. However, for some outcomes, most notably depression and anxiety disorder, associations with suicidal self harm were attenuated and as a result evidence for a difference in risk between the two self harm groups was no longer strong. Suicide attempts often occur in the context of psychiatric disorders, ${ }^{39}{ }^{40}$ and a large proportion of participants with suicide attempts were found to have probable depression and excluded (77\%). The findings therefore need to be interpreted with caution as, given the wide confidence intervals we cannot conclude that the parameter estimates have changed.

\section{Strengths and weaknesses of this study}

This is the first longitudinal study in the United Kingdom to examine outcomes of self harm in a general population sample, and it is the first study to investigate differences in clinical and social outcomes according to suicidal intent. Existing follow-up studies have primarily been conducted in clinical samples, which account for less than $20 \%$ of self harm episodes in the community. ${ }^{2}$ Several different outcomes were examined and we investigated the possible confounding effects of socioeconomic position and previous symptoms of depression, which were assessed at multiple time points throughout adolescence.
The findings need to be interpreted in light of several limitations. Firstly, responders and non-responders to the self harm questionnaire administered at age 16 years differed on a range of characteristics, showing that the data were not missing completely at random, and this non-random response may have biased our complete case analyses. However, we also performed analyses using imputed data and results were consistent with the complete case analyses. Under the missing at random assumption, multiple imputation should correct biases that may arise in the complete case analyses. Although we cannot say with certainty that the data are missing at random, our imputation models included a wealth of auxiliary information, which increases the plausibility of the missing at random assumption. Secondly, we were not able to distinguish those who had self harmed with suicidal intent from those who had self harmed without suicidal intent during the past year at age 21 years. Thirdly, we cannot rule out the possibility of reverse causation for associations with GCSE qualifications, as these school examinations are generally taken at age 16 years, when self harm was also measured, and the age at onset of self harm was not known. There is also the possibility of residual confounding, whereby associations may be accounted for by an additional unmeasured variable. A final limitation concerns the difficulty inherent in establishing suicidal intent accompanying an episode of self harm. In the present study, determination of suicidal intent was based on self report and may include bias; for example, adolescents may be ambivalent or fluctuate in their intent to die and reports may be influenced by current mood state or change over time. This may result in some individuals being classified as having self harmed with suicidal intent who did not truly intend to end their life. However, our approach is in line with previous research, ${ }^{15}$ where individuals are classified as having a history of suicidal self harm if they report any "non-zero" level of self reported suicidal intent.

Our findings are consistent with follow-up studies of people with self harm presenting clinically, which have found an increased risk of psychiatric disorder, future self harm, and substance use problems in adulthood, ${ }^{67}$ compared with those without a history of self harm. We extended this by investigating outcomes in a population based sample of adolescents. Such studies are of critical importance as most acts of self harm do not present to specialist services ${ }^{3}$; for example, in the present sample, only $8.4 \%$ of respondents reported having sought medical help from a doctor or hospital department after their most recent self harm act. Our findings are also consistent with longitudinal population studies, which have found associations between adolescent suicide attempts and poor outcomes in adulthood. ${ }^{11}{ }^{12}$ We provide an extension to this previous work by differentiating between self harm with suicidal intent and self harm without suicidal intent. This is important, as the extent to which suicidal and non-suicidal self harm should be considered different diagnostic categories is a source of debate, ${ }^{13-16}$ and non-suicidal self injury has now been included under "conditions for further study" in the Diagnostic and Statistical Manual, fifth edition. Similar to the findings from Moran et al's longitudinal population study, where adolescents were followed to age 29 years, ${ }^{10}$ we found an overall reduction in the prevalence of self harm over time; the prevalence of self harm in the past year was $16.4 \%$ at age 16 years and $7.3 \%$ at age 21 years. However, whereas Moran et al found that 9 out of 10 adolescents who self harmed reported no further episodes of self harm in adulthood, we found strong evidence for a high level of continuity in self harm between age 16 and 21 years. It is possible that the strong associations found with future self 
harm in this study may begin to attenuate over future assessments.

\section{Clinical implications}

Self harm in adolescents is strongly associated with mental health problems, future self harm, and substance misuse in early adulthood, and suicidal self harm is also associated with poorer educational and occupational outcomes. However, it cannot be assumed that this association is causal, particularly as we are unable to rule out the possibility of residual confounding. Rather, our findings suggest that self harm itself acts as an important risk marker for adverse outcomes in adulthood, over and above previously existing psychopathology. Our findings add to the international debate about the extent to which these self harm behaviours represent distinct concepts or part of a continuum of suicidal behaviour. ${ }^{13-16}$ Although associations were generally stronger in relation to suicidal self harm, non-suicidal self harm was also associated with adverse outcomes in adulthood. This underscores the need for early identification and treatment of adolescents who self harm, regardless of the history of suicidal intent, to alleviate current distress and reduce the risk of future problems. The strong associations with later mental health and substance use found in this study suggest that interventions aimed at reducing self harm behaviours should also focus on treating or preventing these additional problems. This approach may help to reduce the risk of future suicide among young people who self harm, as studies have suggested that those with a history of self harm are more likely to die by suicide if they have mental health or substance use problems. ${ }^{841}$

\section{Unanswered questions and future research}

The interpersonal theory of suicide proposes that non-suicidal self harm may act as a "gateway" to suicidal self harm and completed suicide, as people habituate to the pain and fear of harm through repeated exposure to self harm. ${ }^{42}{ }^{43}$ In future work with this cohort we will examine whether those who had engaged only in non-suicidal self harm at 16 years went on to harm themselves with suicidal intent. Unfortunately we were unable to differentiate between self harm with suicidal intent and self harm without suicidal intent in the past year at age 21 years and were therefore unable to examine these outcomes separately in this study. We were also unable to investigate associations between self harm and future deaths from suicide; the incidence of suicide in 15-19 year olds is low, at fewer than 5 per 100000 per year, and so much larger cohorts are required to investigate this outcome.

Future work with this cohort will enable us to investigate outcomes further into adulthood in order to examine the longer term clinical relevance of self harm in adolescents and investigate the possible mechanisms through which self harm may increase the risk of future psychopathology. Further research is also required to identify characteristics that differentiate between adolescents who self harm and go on to experience problems in adulthood from those who do not, as this may help to ensure that interventions are effectively targeted at those most in need.

We thank the families who took part in this study; the midwives for their help in recruiting the families; the ALSPAC team, which includes interviewers, computer and laboratory technicians, clerical workers, research scientists, volunteers, managers, receptionists, and nurses; and Judi Kidger for her contribution to the development of the self harm questions included in the age 16 year questionnaire.
Study registration: A database of all ALSPAC research proposals can be found at https://alspac.cse.bris.ac.uk/researchproposals/rps/. The present study was approved in July 2011, prior to the collection and analysis of the study data. The analysis proceeded as outlined in the grant proposal.

Contributors: DG, JH, KT, CC, KH, GL, and JM conceived and designed the study. BM, DG, and JH organised the conduct of the study. BM, JH, and DG carried out the study (including acquiring the study data), BM and $\mathrm{JH}$ analysed the data. $\mathrm{BM}, \mathrm{JH}, \mathrm{DG}, \mathrm{KT}, \mathrm{CC}, \mathrm{KH}, \mathrm{GL}$, and JM interpreted the data. BM drafted the manuscript. DG, JH, KT, CC, KH, $\mathrm{GL}$, and $\mathrm{JM}$ criticised the manuscript for important intellectual content. All authors have read and approved the final version of the manuscript. $\mathrm{BM}$ serves as guarantor. DG, $\mathrm{KH}$, and $\mathrm{GL}$ are senior investigators for the National Institute for Health Research. BM and JH had full access to all of the data and can take responsibility for the integrity of the data and the accuracy of the data analysis. $\mathrm{CC}, \mathrm{KH}, \mathrm{GL}, \mathrm{JM}, \mathrm{KT}$, and DG had access to the statistical outputs, reports, and tables. All researchers are independent of the funding bodies.

Funding: ALSPAC receives core support from the UK Medical Research Council and the Wellcome Trust (grant reference 092731) and the University of Bristol. This research was specifically funded by the Medical Research Council to study the causes and consequences of self harm with and without suicidal intent in adolescence (grant reference MR/J012661/1). The study sponsor had no further role in the study design; the collection, analysis, and interpretation of data; or the writing of the article and the decision to submit it for publication.

Competing interests: All authors have completed the ICMJE uniform disclosure form at www.icmje.org/coi_disclosure.pdf and declare: the research was funded by the Medical Research Council); no financial relationships with any organisations that might have an interest in the submitted work in the previous three years; no other relationships or activities that could appear to have influenced the submitted work.

Ethical approval: This study was approved by the ALSPAC Law and Ethics Committee and the local research ethics committees.

Data sharing: The ALSPAC policy on data sharing is available at www. bristol.ac.uk/alspac. To discuss access to ALSPAC data, please contact the ALSPAC executive team on alspac-exec@bristol.ac.uk.

Transparency: The lead author (BM) affirms that the manuscript is an honest, accurate, and transparent account of the study being reported; that no important aspects of the study have been omitted; and that any discrepancies from the study as planned (and, if relevant, registered) have been explained.

1 Evans E, Hawton K, Rodham K, Psychol C, Deeks J. The prevalence of suicidal phenomena in adolescents: a systematic review of population-based studies. Suicide Life Threat Behav 2005;35:239-50.

2 Kidger J, Heron J, Lewis G, Evans J, Gunnell D. Adolescent self-harm and suicidal thoughts in the ALSPAC cohort: A self-report survey in England. BMC Psychiatry 2012;12:69.

3 Hawton K, Rodham K, Evans E, Weatherall R. Deliberate self harm in adolescents: self report survey in schools in England. BMJ 2002;325:1207-11.

4 Madge N, Hewitt A, Hawton K, de Wilde EJ, Corcoran P, Fekete S, et al. Deliberate self-harm within an international community sample of young people: comparative findings self-harm within an international community sample of young people: comparative findings
from the Child \& Adolescent Self-harm in Europe (CASE) Study. J Child Psychol Psychiatry 2008;49:667-77.

5 Klonsky ED, Muehlenkamp JJ. Self-injury: a research review for the practitioner. J Clin Psychol 2007;63:1045-56.

6 Groholt B, Ekeberg Ø. Prognosis after adolescent suicide attempt: mental health, psychiatric treatment, and suicide attempts in a nine-year follow-up study. Suicide Life Threat Behav 2009;39:125-36.

7 Harrington R, Pickles A, Aglan A, Harrington V, Burroughs H, Kerfoot M. Early adult outcomes of adolescents who deliberately poisoned themselves. J Am Academy Child Adolesc Psychiatry 2006;45:337-45.

8 Hawton K, Harriss L. Deliberate self-harm in young people: characteristics and subsequent mortality in a 20 -Year cohort of patients presenting to hospital. J Clin Psychiatry 2007;68:1574.

9 Hawton K, Harriss L. Deliberate self-harm by under-15-year-olds: characteristics, trends and outcome. J Child Psychol Psychiatry 2008;49:441-8.

10 Moran P, Coffey C, Romaniuk H, Olsson C, Borschmann R, Carlin JB, et al. The natural history of self-harm from adolescence to young adulthood: a population-based cohort study. Lancet 2012;379:236-43.

11 Goldman-Mellor S, Caspi A, Harrington H, Hogan S, Nada-Raja S, Poulton R, et al. Suicide attempt in young people: a signal for long-term healthcare and social needs. JAMA Psychiatry 2014;71:119-27. 


\section{What is already known on this topic}

Little is known about the longer term clinical and social outcomes of self harm in adolescents and whether outcomes differ among those who self harm with suicidal intent and those who self harm without suicidal intent

Existing knowledge is largely based on findings from clinical populations; however, most people who self harm do not present to services

\section{What this study adds}

Our study suggests that self harm in adolescents in the general population is a risk marker for future mental health, self harm, and substance use problems in early adulthood, regardless of suicidal intent

Suicidal self harm is also a risk marker for poorer educational and occupational outcomes

Associations with adverse outcomes are generally stronger for self harm with suicidal intent than for self harm without suicidal intent

12 Fergusson DM, Horwood LJ, Ridder EM, Beautrais AL. Suicidal behaviour in adolescence and subsequent mental health outcomes in young adulthood. Psychol Med 2005;35:983-94

13 Kapur N, Cooper J, O'Connor RC, Hawton K. Non-suicidal self-injury v. attempted suicide: new diagnosis or false dichotomy? Br J Psychiatry 2013;202:326-8.

14 Muehlenkamp JJ, Kerr PL. Untangling a complex web: how non-suicidal self-injury and suicide attempts differ. Prev Res 2010;17:8-10.

15 Nock MK. Self-injury. Ann Rev Clin Psychol 2010;6:339-63.

16 Stanley B, Winchel R, Molcho A, Simeon D, Stanley M. Suicide and the self-harm continuum: phenomenological and biochemical evidence. Int Rev Psychiatry 1992;4:149-55.

17 Wilkinson P. Non-suicidal self-injury. Eur Child Adolesc Psychiatry 2013;22:75-9.

18 Wichstrøm L. Predictors of non-suicidal self-injury versus attempted suicide: similar or different? Arch Suicide Res 2009:13:105-22.

19 Hargus E, Hawton K, Rodham K. Distinguishing between subgroups of adolescents who self-harm. Suicide Life Threat Behav 2009;39:518-37.

20 Mars B, Heron J, Crane C, Hawton K, Kidger J, Lewis G, et al. Differences in risk factors for self-harm with and without suicidal intent: Findings from the ALSPAC cohort. $J$ Affect Disord 2014;168:407-14.

21 Boyd A, Golding J, Macleod J, Lawlor DA, Fraser A, Henderson J, et al. Cohort profile: the 'Children of the 90s'-the index offspring of the Avon Longitudinal Study of Parents and Children. Int J Epidemiol 2013;42:111-27.

22 Muehlenkamp JJ, Gutierrez PM. Risk for suicide attempts among adolescents who engage in non-suicidal self-injury. Arch Suicide Res 2007;11:69-82.

23 Brausch AM, Gutierrez PM. Differences in non-suicidal self-injury and suicide attempts in adolescents. $J$ Youth Adolesc 2010;39:233-42.

24 Zetterqvist M, Lundh L-G, Svedin CG. A comparison of adolescents engaging in self-injurious behaviors with and without suicidal intent: self-reported experiences of adverse life events and trauma symptoms. J Youth Adolesc 2013;42:1257-72.

25 Lewis G, Pelosi AJ, Araya R, Dunn G. Measuring psychiatric disorder in the community: a standardized assessment for use by lay interviewers. Psychol Med 1992;22:465-86.

26 Patton G, Coffey C, Posterino M, Carlin J, Wolfe R, Bowes G. A computerised screening instrument for adolescent depression: population-based validation and application to a two-phase case-control study. Soc Psychiatry Psychiatr Epidemiol 1999;34:166-72.

27 Lewis G. Assessing psychiatric disorder with a human interviewer or a computer. $J$ Epidemiol Community Health 1994;48:207-10

28 Bell T, Watson M, Sharp D, Lyons I, Lewis G. Factors associated with being a false positive on the General Health Questionnaire. Soc Psychiatry Psychiatr Epidemiol 2005:40:402-7.

29 Hospital Episode Statistics. 2014. www.hscic.gov.uk/hes.

30 Saunders JB, Aasland OG, Babor TF, Grant M. Development of the Alcohol Use Disorders Identification Test (AUDIT): WHO collaborative project on early detection of persons with harmful alcohol consumption-II. Addiction 1993;88:791-804.
31 Babor T, Higgins-Biddle J, Saunders JB, Monteiro M. AUDIT: the alcohol use disorders identification test, guidelines for use in primary care, 2 nd edn. Department of Mental Health and Substance Dependence, World Health Organization, 2001.

32 Legleye S, Karila L, Beck F, Reynaud M. Validation of the CAST, a general population Cannabis Abuse Screening Test. J Subst Use 2007;12:233-42.

33 Heron J, Barker ED, Joinson C, Lewis G, Hickman M, Munafò M, et al. Childhood conduc disorder trajectories, prior risk factors and cannabis use at age 16: birth cohort study. Addiction 2013;108:2129-38.

34 Office for National Statistics. Young People Not in Education, Employment or Training (NEET). May 2013.

35 Messer SC, Angold A, Costello EJ, Loeber R, Van Kammen W, Stouthamer-Loeber M. Development of a short questionnaire for use in epidemiological studies of depression in children and adolescents: factor composition and structure across development. Int $J$ Methods Psychiatr Res 1995;5:251-62.

36 Wechsler D. Wechsler intelligence scale for children, 3rd UK ed. Psychological Corporation, 1991.

37 Royston P, White IR. Multiple Imputation by Chained Equations (MICE): implementation in Stata. J Stat Softw 2011;45:1-20.

38 Sterne JA, White IR, Carlin JB, Spratt M, Royston P, Kenward MG, et al. Multiple imputation for missing data in epidemiological and clinical research: potential and pitfalls. $B M J$ 2009;338:b2393.

39 Hawton K, Saunders K, Topiwala A, Haw C. Psychiatric disorders in patients presenting to hospital following self-harm: a systematic review. J Affect Disord 2013;151:821-30.

40 Evans E, Hawton K, Rodham K. Factors associated with suicidal phenomena in adolescents: a systematic review of population-based studies. Clin Psychol Rev 2004:24:957-79.

41 Hawton K, Fagg J, Platt S, Hawkins M. Factors associated with suicide after parasuicide in young people. BMJ 1993;306:1641.

42 Joiner T. Why people die by suicide. Harvard University Press, 2009.

43 Van Orden KA, Witte TK, Cukrowicz KC, Braithwaite SR, Selby EA, Joiner TE Jr. The interpersonal theory of suicide. Psychol Rev 2010;117:575.

\section{Accepted: 24 September 2014}

\section{Cite this as: BMJ 2014;349:g5954}

This is an Open Access article distributed in accordance with the terms of the Creative Commons Attribution (CC BY 4.0) license, which permits others to distribute, remix, adapt and build upon this work, for commercial use, provided the original work is properly cited. See: http://creativecommons.org/licenses/by/4.0/. 


\section{Tables}

Table 1| Outcomes in early adulthood (age 16-21 years) for participants who had self harmed with and without suicidal intent by age 16 years. Values are numerators/denominators (percentages) unless stated otherwise

\begin{tabular}{|c|c|c|c|c|c|}
\hline Outcomes & No in sample & No self harm by age 16 & $\begin{array}{c}\text { Non-suicidal self harm by } \\
\text { age } 16\end{array}$ & $\begin{array}{l}\text { Suicidal self harm by age } \\
\qquad 16\end{array}$ & $P$ value \\
\hline \multicolumn{6}{|l|}{ Mental health and future self harm: } \\
\hline CIS-R depressive disorder (age 18) & 2944 & $126 / 2386(5.3)$ & $49 / 370(13.2)$ & $45 / 188(23.9)$ & $<0.001$ \\
\hline CIS-R anxiety disorder (age 18) & 2944 & $176 / 2386(7.4)$ & $69 / 370(18.7)$ & $65 / 188(34.6)$ & $<0.001$ \\
\hline Self harm in past year (age 21) & 3069 & $88 / 2504(3.5)$ & $66 / 376(17.6)$ & $69 / 189(36.5)$ & $<0.001$ \\
\hline \multicolumn{6}{|l|}{ Substance use (age 18): } \\
\hline Harmful alcohol use & 2840 & $86 / 2299(3.7)$ & 29/354 (8.2) & 19/187 (10.2) & $<0.001$ \\
\hline Problem cannabis use & 2833 & $46 / 2294(2.0)$ & $22 / 353(6.2)$ & $27 / 186(14.5)$ & $<0.001$ \\
\hline Smoking regularly & 2850 & $256 / 2311(11.1)$ & $98 / 353(27.8)$ & $64 / 186(34.4)$ & $<0.001$ \\
\hline Illicit drug use & 2822 & $191 / 2288(8.4)$ & $70 / 349(20.1)$ & $47 / 185(25.4)$ & $<0.001$ \\
\hline \multicolumn{6}{|l|}{ Education and occupation: } \\
\hline $\begin{array}{l}\text { Did not achieve } \geq 5 \text { GCSEs or } \\
\text { equivalent } A^{*}-C \text { grades (age 15-16) }\end{array}$ & 4019 & $470 / 3260(14.4)$ & $54 / 476(11.3)$ & $78 / 283(27.6)$ & $<0.001$ \\
\hline $\begin{array}{l}\text { Did not achieve } \geq 3 \mathrm{~A} \text { level } \\
\text { qualifications (age 19) }\end{array}$ & 2346 & $902 / 1914(47.1)$ & $122 / 283(43.1)$ & $87 / 149(58.4)$ & 0.009 \\
\hline NEET (age 19) & 2684 & $116 / 2185(5.3)$ & $19 / 318(6.0)$ & $17 / 181(9.4)$ & 0.071 \\
\hline
\end{tabular}

CIS-R=clinical interview schedule, revised; NEET=not in education, employment, or training.

Of 4799 respondents with information on self harm at age 16, the number with missing outcome data was 1855 for CIS-R depressive disorder (38.7\%), 1855 for CIS-R anxiety disorder (38.7\%), 1730 for self harm in past year at age 21 (36.1\%), 1959 for harmful alcohol use (40.8\%), 1966 for problem cannabis use (41.0\%), 1949 for regular smoking (40.6\%), 1977 for illicit drug use (41.2\%), 780 for not achieving five or more GCSEs or equivalent $A^{*}$-C grades (16.3\%), 2453 for not achieving three or more A levels (51.1\%), and 2115 for NEET (44.1\%). 
Table 2| Associations of self harm with and without suicidal intent with mental health, substance use, educational, and occupational outcomes in early adulthood, $n=4799$ (results after imputation)

\begin{tabular}{|c|c|c|c|c|c|c|}
\hline \multirow{2}{*}{$\begin{array}{l}\text { Self harm and suicidal intent by } \\
\text { outcomes }\end{array}$} & \multicolumn{2}{|c|}{ Adjusted for sex } & \multicolumn{2}{|c|}{ Adjusted for sex and SEP } & \multicolumn{2}{|c|}{$\begin{array}{c}\text { Adjusted for sex, SEP, and } \\
\text { depression symptoms }\end{array}$} \\
\hline & Odds ratio $(95 \% \mathrm{Cl})$ & $P$ value & Odds ratio $(95 \% \mathrm{Cl})$ & $P$ value & Odds ratio $(95 \% \mathrm{Cl})$ & $P$ value \\
\hline \multicolumn{7}{|c|}{ Mental health outcomes and future self harm } \\
\hline \multicolumn{7}{|l|}{$\begin{array}{l}\text { CIS-R depressive disorder (age } \\
\text { 18): }\end{array}$} \\
\hline $\begin{array}{l}\text { Non-suicidal self harm } v \text { no self } \\
\text { harm }\end{array}$ & 2.44 (1.73 to 3.44$)$ & $<0.001$ & $2.47(1.75$ to 3.48$)$ & $<0.001$ & 2.21 (1.55 to 3.15$)$ & $<0.001$ \\
\hline Suicidal self harm $v$ no self harm & 4.97 (3.42 to 7.20$)$ & & 4.87 (3.36 to 7.08$)$ & & 3.94 (2.67 to 5.83$)$ & \\
\hline $\begin{array}{l}\text { Suicidal self harm } v \text { non-suicidal } \\
\text { self harm }\end{array}$ & 2.04 (1.35 to 3.06$)$ & & 1.98 (1.31 to 2.97$)$ & & $1.78(1.18$ to 2.71$)$ & \\
\hline \multicolumn{7}{|l|}{ CIS-R anxiety disorder (age 18) } \\
\hline $\begin{array}{l}\text { Non-suicidal self harm } v \text { no self } \\
\text { harm }\end{array}$ & 2.39 (1.76 to 3.25$)$ & $<0.001$ & 2.41 (1.77 to 3.28$)$ & $<0.001$ & 2.15 (1.57 to 2.95$)$ & $<0.001$ \\
\hline Suicidal self harm $v$ no self harm & 5.55 (4.07 to 7.55$)$ & & $5.50(4.04$ to 7.50$)$ & & 4.47 (3.24 to 6.16$)$ & \\
\hline $\begin{array}{l}\text { Suicidal self harm } v \text { non-suicidal } \\
\text { self harm }\end{array}$ & 2.32 (1.57 to 3.42$)$ & & 2.28 (1.55 to 3.37$)$ & & 2.07 (1.39 to 3.10$)$ & \\
\hline \multicolumn{7}{|l|}{ Self harm in past year (age 21): } \\
\hline $\begin{array}{l}\text { Non-suicidal self harm } v \text { no self } \\
\text { harm }\end{array}$ & 4.60 (3.23 to 6.54$)$ & $<0.001$ & 4.68 (3.28 to 6.67$)$ & $<0.001$ & 4.48 (3.13 to 6.41$)$ & $<0.001$ \\
\hline Suicidal self harm $v$ no self harm & $12.6(8.91$ to 17.8$)$ & & $12.4(8.78$ to 17.6$)$ & & $11.4(7.90$ to 16.4$)$ & \\
\hline $\begin{array}{l}\text { Suicidal self harm } v \text { non-suicidal } \\
\text { self harm }\end{array}$ & 2.74 (1.87 to 40.2$)$ & & 2.66 (1.80 to 3.91$)$ & & 2.54 (1.72 to 3.77$)$ & \\
\hline \multicolumn{7}{|l|}{ Substance use outcomes } \\
\hline \multicolumn{7}{|l|}{ Harmful alcohol use (age 18): } \\
\hline $\begin{array}{l}\text { Non-suicidal self harm } v \text { no self } \\
\text { harm }\end{array}$ & 2.01 (1.33 to 3.03$)$ & $<0.001$ & 2.03 (1.35 to 3.07$)$ & $<0.001$ & 1.89 (1.24 to 2.86$)$ & 0.002 \\
\hline Suicidal self harm $v$ no self harm & 2.37 (1.43 to 3.94$)$ & & 2.29 (1.38 to 3.81$)$ & & 1.95 (1.17 to 3.26$)$ & \\
\hline $\begin{array}{l}\text { Suicidal self harm } v \text { non-suicidal } \\
\text { self harm }\end{array}$ & 1.18 (0.66 to 2.13$)$ & & $1.13(0.62$ to 2.04$)$ & & 1.03 (0.57 to 1.87$)$ & \\
\hline \multicolumn{7}{|l|}{ Problem cannabis use (age 18): } \\
\hline $\begin{array}{l}\text { Non-suicidal self harm } v \text { no self } \\
\text { harm }\end{array}$ & 2.78 (1.72 to 4.52$)$ & $<0.001$ & 2.89 (1.77 to 4.72$)$ & $<0.001$ & 2.75 (1.68 to 4.50$)$ & $<0.001$ \\
\hline Suicidal self harm $v$ no self harm & $6.46(3.94$ to 10.6$)$ & & $6.42(3.89$ to 10.6$)$ & & 5.77 (3.46 to 9.63$)$ & \\
\hline $\begin{array}{l}\text { Suicidal self harm } v \text { non-suicidal } \\
\text { self harm }\end{array}$ & 2.32 (1.31 to 4.10$)$ & & 2.22 (1.25 to 3.95$)$ & & 2.10 (1.17 to 3.75$)$ & \\
\hline \multicolumn{7}{|l|}{ Smoking regularly (age 18): } \\
\hline $\begin{array}{l}\text { Non-suicidal self harm } v \text { no self } \\
\text { harm }\end{array}$ & 2.58 (2.00 to 3.34$)$ & $<0.001$ & 2.64 (2.04 to 3.43 ) & $<0.001$ & 2.58 (1.99 to 3.56$)$ & $<0.001$ \\
\hline Suicidal self harm $v$ no self harm & 3.66 (2.70 to 4.96$)$ & & 3.58 (2.63 to 4.87$)$ & & 3.41 (2.49 to 4.66$)$ & \\
\hline $\begin{array}{l}\text { Suicidal self harm } v \text { non-suicidal } \\
\text { self harm }\end{array}$ & $1.42(1.00$ to 2.00$)$ & & 1.35 (0.96 to 1.92$)$ & & 1.32 (0.93 to 1.87$)$ & \\
\hline \multicolumn{7}{|l|}{ Illicit drug use (age 18): } \\
\hline $\begin{array}{l}\text { Non-suicidal self harm } v \text { no self } \\
\text { harm }\end{array}$ & 2.86 (2.11 to 3.87$)$ & $<0.001$ & 2.82 (2.08 to 3.82$)$ & $<0.001$ & 2.65 (1.94 to 3.60$)$ & $<0.001$ \\
\hline Suicidal self harm $v$ no self harm & 3.46 (2.43 to 4.94$)$ & & 3.64 (2.53 to 5.22$)$ & & $3.20(2.21$ to 4.64$)$ & \\
\hline $\begin{array}{l}\text { Suicidal self harm } v \text { non-suicidal } \\
\text { self harm }\end{array}$ & $1.21(0.81$ to 1.82$)$ & & $1.29(0.86$ to 1.95$)$ & & $1.21(0.80$ to 1.83$)$ & \\
\hline \multicolumn{7}{|c|}{ Educational and occupational outcomes } \\
\hline \multicolumn{7}{|l|}{$\begin{array}{l}\text { Did not achieve } \geq 5 \text { GCSEs or } \\
\text { equivalent } A^{*}-C \text { grades (age } \\
15-16 \text { ): }\end{array}$} \\
\hline $\begin{array}{l}\text { Non-suicidal self harm } v \text { no self } \\
\text { harm }\end{array}$ & $0.83(0.62$ to 1.11$)$ & $<0.001$ & $0.89(0.65$ to 1.21$)$ & $<0.001$ & 1.15 (0.81 to 1.63$)$ & $<0.001$ \\
\hline Suicidal self harm $v$ no self harm & 2.24 (1.70 to 2.95$)$ & & 2.13 (1.59 to 2.86$)$ & & 2.08 (1.47 to 2.95$)$ & \\
\hline
\end{tabular}




\section{Table 2 (continued)}

\begin{tabular}{|c|c|c|c|c|c|c|}
\hline \multirow{2}{*}{$\begin{array}{l}\text { Self harm and suicidal intent by } \\
\text { outcomes }\end{array}$} & \multicolumn{2}{|c|}{ Adjusted for sex } & \multicolumn{2}{|c|}{ Adjusted for sex and SEP } & \multicolumn{2}{|c|}{$\begin{array}{l}\text { Adjusted for sex, SEP, and } \\
\text { depression symptoms }{ }^{\star}\end{array}$} \\
\hline & Odds ratio $(95 \% \mathrm{Cl})$ & $P$ value & Odds ratio $(95 \% \mathrm{Cl})$ & $P$ value & Odds ratio $(95 \% \mathrm{Cl})$ & $P$ value \\
\hline $\begin{array}{l}\text { Suicidal self harm } v \text { non-suicidal } \\
\text { self harm }\end{array}$ & 2.71 (1.87 to 3.94$)$ & & 2.40 (1.62 to 3.55$)$ & & 1.81 (1.16 to 2.82 ) & \\
\hline \multicolumn{7}{|l|}{$\begin{array}{l}\text { Did not achieve } \geq 3 \text { A level } \\
\text { qualifications (age 19): }\end{array}$} \\
\hline $\begin{array}{l}\text { Non-suicidal self harm } v \text { no self } \\
\text { harm }\end{array}$ & 0.85 (0.67 to 1.08$)$ & 0.007 & 0.88 (0.69 to 1.13$)$ & 0.052 & 0.95 (0.73 to 1.23$)$ & 0.229 \\
\hline Suicidal self harm $v$ no self harm & 1.53 (1.12 to 2.09$)$ & & $1.42(1.01$ to 1.98$)$ & & 1.34 (0.93 to 1.92$)$ & \\
\hline $\begin{array}{l}\text { Suicidal self harm } v \text { non-suicidal } \\
\text { self harm }\end{array}$ & 1.79 (1.22 to 2.63$)$ & & 1.61 (1.07 to 2.43$)$ & & $1.41(0.91$ to 2.19$)$ & \\
\hline \multicolumn{7}{|l|}{ NEET (age 19): } \\
\hline $\begin{array}{l}\text { Non-suicidal self harm } v \text { no self } \\
\text { harm }\end{array}$ & $1.26(0.78$ to 2.05$)$ & 0.023 & $1.29(0.79$ to 2.11$)$ & 0.034 & 1.41 (0.86 to 2.33$)$ & 0.031 \\
\hline Suicidal self harm $v$ no self harm & 2.03 (1.22 to 3.36$)$ & & 1.95 (1.17 to 3.25$)$ & & $1.96(1.16$ to 3.31$)$ & \\
\hline $\begin{array}{l}\text { Suicidal self harm } v \text { non-suicidal } \\
\text { self harm }\end{array}$ & $1.61(0.84$ to 3.06$)$ & & 1.51 (0.79 to 2.88$)$ & & 1.39 (0.72 to 2.68$)$ & \\
\hline
\end{tabular}

$\mathrm{CIS}-\mathrm{R}=$ clinical interview schedule, revised; $\mathrm{SEP}=$ socioeconomic position (includes maternal education and parental social class), assessed during pregnancy; NEET=not in education, employment, or training.

Omnibus $P$ values test for difference in odds across three levels of self harm.

Data presented based on an imputed sample of 4799 . Number of respondents with complete data on outcome and all included covariates was 2554 for CIS-R depressive disorder, 2554 for CIS-R anxiety disorder, 2437 for self harm in past year at age 21, 2476 for harmful alcohol use, 2470 for problem cannabis use, 2482 for regular smoking, 2462 for illicit drug use, 2777 for not achieving five or more GCSEs or equivalent $A^{*}$-C grades, 1743 for not achieving three or more $A$ levels, and 1972 for NEET.

*Educational and occupational outcomes additionally adjusted for IQ at age 8 years. 
Table 3| Associations of self harm with and without suicidal intent with outcomes in early adulthood, excluding those with evidence of previous problems (results after imputation)

\begin{tabular}{|c|c|c|c|c|c|c|}
\hline \multirow{2}{*}{$\begin{array}{l}\text { Self harm and suicidal } \\
\text { intent by outcomes }\end{array}$} & \multicolumn{2}{|c|}{ Adjusted for sex } & \multicolumn{2}{|c|}{ Adjusted for sex and SEP } & \multicolumn{2}{|c|}{$\begin{array}{c}\text { Adjusted for sex, SEP, and } \\
\text { depression symptoms }{ }^{\star}\end{array}$} \\
\hline & Odds ratio $(95 \% \mathrm{Cl})$ & $P$ value & Odds ratio $(95 \% \mathrm{Cl})$ & $P$ value & Odds ratio $(95 \% \mathrm{Cl})$ & $P$ value \\
\hline \multicolumn{7}{|c|}{ Mental health outcomes and future self harm } \\
\hline \multicolumn{7}{|l|}{$\begin{array}{l}\text { CIS-R depressive disorder (age } \\
\text { 18): }\end{array}$} \\
\hline $\begin{array}{l}\text { Non-suicidal self harm } v \text { no } \\
\text { self harm }\end{array}$ & 3.10 (1.84 to 5.23$)$ & $<0.001$ & $3.12(1.85$ to 5.26$)$ & $<0.001$ & 3.08 (1.83 to 5.19$)$ & $<0.001$ \\
\hline $\begin{array}{l}\text { Suicidal self harm } v \text { no self } \\
\text { harm }\end{array}$ & 2.45 (0.83 to 7.25$)$ & & $2.43(0.81$ to 7.22$)$ & & $2.39(0.80$ to 7.11$)$ & \\
\hline $\begin{array}{l}\text { Suicidal self harm } v \\
\text { non-suicidal self harm }\end{array}$ & $0.79(0.25$ to 2.47$)$ & & $0.78(0.25$ to 2.45$)$ & & $0.78(0.25$ to 2.44$)$ & \\
\hline $\begin{array}{l}\text { CIS-R anxiety disorder (age } \\
18):\end{array}$ & & $<0.001$ & & $<0.001$ & & $<0.001$ \\
\hline $\begin{array}{l}\text { Non-suicidal self harm } v \text { no } \\
\text { self harm }\end{array}$ & $2.30(1.41$ to 3.75$)$ & & $2.30(1.41$ to 3.77$)$ & & 2.27 (1.39 to 3.72$)$ & \\
\hline $\begin{array}{l}\text { Suicidal self harm } v \text { no self } \\
\text { harm }\end{array}$ & $2.75(1.18$ to 6.40$)$ & & $2.74(1.17$ to 6.39$)$ & & 2.69 (1.15 to 6.28$)$ & \\
\hline $\begin{array}{l}\text { Suicidal self harm } v \\
\text { non-suicidal self harm }\end{array}$ & $1.20(0.47$ to 3.02$)$ & & $1.19(0.47$ to 3.02$)$ & & $1.18(0.46$ to 3.01$)$ & \\
\hline \multicolumn{7}{|l|}{ Self harm in past year (age 21): } \\
\hline $\begin{array}{l}\text { Non-suicidal self harm } v \text { no } \\
\text { self harm }\end{array}$ & 4.66 (2.88 to 7.54$)$ & $<0.001$ & 4.74 (2.93 to 7.68$)$ & $<0.001$ & 4.69 (2.89 to 7.61$)$ & $<0.001$ \\
\hline $\begin{array}{l}\text { Suicidal self harm } v \text { no self } \\
\text { harm }\end{array}$ & $14.9(7.57$ to 29.4$)$ & & $14.9(7.54$ to 29.4$)$ & & 14.7 (7.42 to 29.0$)$ & \\
\hline $\begin{array}{l}\text { Suicidal self harm } v \\
\text { non-suicidal self harm }\end{array}$ & $3.20(1.55$ to 6.61$)$ & & $3.14(1.52$ to 6.49$)$ & & $3.13(1.51$ to 6.48$)$ & \\
\hline \multicolumn{7}{|l|}{ Substance use outcomes } \\
\hline \multicolumn{7}{|l|}{ Harmful alcohol use (age 18): } \\
\hline $\begin{array}{l}\text { Non-suicidal self harm } v \text { no } \\
\text { self harm }\end{array}$ & $1.82(0.95$ to 3.51$)$ & 0.056 & $1.83(0.95$ to 3.51$)$ & 0.062 & $1.72(0.89$ to 3.33$)$ & 0.128 \\
\hline $\begin{array}{l}\text { Suicidal self harm } v \text { no self } \\
\text { harm }\end{array}$ & 2.05 (0.96 to 4.36$)$ & & 1.99 (0.93 to 4.26$)$ & & 1.77 (0.82 to 3.82$)$ & \\
\hline $\begin{array}{l}\text { Suicidal self harm } v \\
\text { non-suicidal self harm }\end{array}$ & $1.12(0.44$ to 2.87$)$ & & $1.09(0.42$ to 2.79$)$ & & $1.03(0.40$ to 2.63$)$ & \\
\hline \multicolumn{7}{|l|}{$\begin{array}{l}\text { Problem cannabis use (age } \\
18):\end{array}$} \\
\hline $\begin{array}{l}\text { Non-suicidal self harm } v \text { no } \\
\text { self harm }\end{array}$ & $1.74(0.58$ to 5.21$)$ & 0.015 & $1.81(0.60$ to 5.46$)$ & 0.016 & 1.75 (0.58 to 5.29$)$ & 0.026 \\
\hline $\begin{array}{l}\text { Suicidal self harm } v \text { no self } \\
\text { harm }\end{array}$ & 4.04 (1.60 to 10.2$)$ & & $4.03(1.59$ to 10.2$)$ & & 3.77 (1.46 to 9.70$)$ & \\
\hline $\begin{array}{l}\text { Suicidal self harm } v \\
\text { non-suicidal self harm }\end{array}$ & $2.32(0.60$ to 9.01$)$ & & $2.23(0.57$ to 8.68$)$ & & 2.15 (0.55 to 8.42$)$ & \\
\hline \multicolumn{7}{|l|}{ Smoking regularly(age 18$)$ : } \\
\hline $\begin{array}{l}\text { Non-suicidal self harm } v \text { no } \\
\text { self harm }\end{array}$ & 3.01 (1.96 to 4.62$)$ & $<0.001$ & 3.05 (1.98 to 4.69$)$ & $<0.001$ & 3.05 (1.97 to 4.72$)$ & $<0.001$ \\
\hline $\begin{array}{l}\text { Suicidal self harm } v \text { no self } \\
\text { harm }\end{array}$ & 2.51 (1.28 to 4.92$)$ & & $2.49(1.27$ to 4.88$)$ & & 2.49 (1.26 to 4.92$)$ & \\
\hline $\begin{array}{l}\text { Suicidal self harm } v \\
\text { non-suicidal self harm }\end{array}$ & $0.83(0.41$ to 1.70$)$ & & $0.82(0.40$ to 1.66$)$ & & $0.82(0.40$ to 1.66$)$ & \\
\hline \multicolumn{7}{|l|}{ Illicit drug use (age 18): } \\
\hline $\begin{array}{l}\text { Non-suicidal self harm } v \text { no } \\
\text { self harm }\end{array}$ & 2.36 (1.40 to 3.98$)$ & $<0.001$ & $2.28(1.35$ to 3.84$)$ & $<0.001$ & $2.18(1.29$ to 3.70$)$ & 0.002 \\
\hline $\begin{array}{l}\text { Suicidal self harm } v \text { no self } \\
\text { harm }\end{array}$ & $2.62(1.29$ to 5.31$)$ & & 2.77 (1.36 to 5.65$)$ & & 2.54 (1.23 to 5.24$)$ & \\
\hline $\begin{array}{l}\text { Suicidal self harm } v \\
\text { non-suicidal self harm }\end{array}$ & $1.11(0.50$ to 2.44$)$ & & $1.22(0.55$ to 2.70$)$ & & $1.16(0.52$ to 2.59$)$ & \\
\hline
\end{tabular}


Table 3 (continued)

\begin{tabular}{|c|c|c|c|c|c|c|}
\hline \multirow{2}{*}{$\begin{array}{l}\text { Self harm and suicidal } \\
\text { intent by outcomes }\end{array}$} & \multicolumn{2}{|c|}{ Adjusted for sex } & \multicolumn{2}{|c|}{ Adjusted for sex and SEP } & \multicolumn{2}{|c|}{$\begin{array}{l}\text { Adjusted for sex, SEP, and } \\
\text { depression symptoms }\end{array}$} \\
\hline & Odds ratio $(95 \% \mathrm{Cl})$ & $P$ value & Odds ratio $(95 \% \mathrm{Cl})$ & $P$ value & Odds ratio $(95 \% \mathrm{Cl})$ & $P$ value \\
\hline \multicolumn{7}{|c|}{ Educational and occupational outcomes } \\
\hline \multicolumn{7}{|l|}{$\begin{array}{l}\text { Did not achieve } \geq 5 \text { GCSEs or } \\
\text { equivalent } A^{*}-C \text { grades (age } \\
\text { 15-16): }\end{array}$} \\
\hline $\begin{array}{l}\text { Non-suicidal self harm } v \text { no } \\
\text { self harm }\end{array}$ & $1.56(0.81$ to 3.00$)$ & $<0.001$ & $1.64(0.85$ to 3.19$)$ & $<0.001$ & 1.75 (0.89 to 3.45$)$ & $<0.001$ \\
\hline $\begin{array}{l}\text { Suicidal self harm } v \text { no self } \\
\text { harm }\end{array}$ & 4.96 (2.70 to 9.13$)$ & & 4.96 (2.67 to 9.21$)$ & & 5.19 (2.72 to 9.92$)$ & \\
\hline $\begin{array}{l}\text { Suicidal self harm } v \\
\text { non-suicidal self harm }\end{array}$ & $3.19(1.46$ to 6.96$)$ & & $3.02(1.37$ to 6.64$)$ & & $2.97(1.31$ to 6.70$)$ & \\
\hline \multicolumn{7}{|l|}{$\begin{array}{l}\text { Did not achieve } \geq 3 \text { A level } \\
\text { qualifications (age 19): }\end{array}$} \\
\hline $\begin{array}{l}\text { Non-suicidal self harm } v \text { no } \\
\text { self harm }\end{array}$ & $0.96(0.70$ to 1.30$)$ & 0.732 & $0.98(0.71$ to 1.35$)$ & 0.861 & $0.98(0.70$ to 1.38$)$ & 0.932 \\
\hline $\begin{array}{l}\text { Suicidal self harm } v \text { no self } \\
\text { harm }\end{array}$ & $1.17(0.75$ to 1.84$)$ & & $1.13(0.71$ to 1.81$)$ & & 1.09 (0.67 to 1.79$)$ & \\
\hline $\begin{array}{l}\text { Suicidal self harm } v \\
\text { non-suicidal self harm }\end{array}$ & $1.23(0.71$ to 2.13$)$ & & $1.16(0.65$ to 2.06$)$ & & $1.11(0.61$ to 2.03$)$ & \\
\hline \multicolumn{7}{|l|}{ NEET (age 19): } \\
\hline $\begin{array}{l}\text { Non-suicidal self harm } v \text { no } \\
\text { self harm }\end{array}$ & 1.57 (0.87 to 2.84$)$ & 0.047 & $1.58(0.87$ to 2.86$)$ & 0.049 & $1.63(0.90$ to 2.96$)$ & 0.038 \\
\hline $\begin{array}{l}\text { Suicidal self harm } v \text { no self } \\
\text { harm }\end{array}$ & 2.35 (1.08 to 5.10$)$ & & 2.33 (1.07 to 5.08$)$ & & 2.43 (1.11 to 5.32$)$ & \\
\hline $\begin{array}{l}\text { Suicidal self harm } v \\
\text { non-suicidal self harm }\end{array}$ & $1.49(0.59$ to 3.77$)$ & & $1.48(0.58$ to 3.76$)$ & & 1.49 (0.58 to 3.79$)$ & \\
\hline
\end{tabular}

$\mathrm{CIS}-\mathrm{R}=$ clinical interview schedule, revised; $\mathrm{SEP}=$ socioeconomic position (includes maternal education and parental social class), assessed during pregnancy; NEET=not in education, employment, or training.

Omnibus $P$ values test for difference in odds across three levels of self harm.

Criteria for exclusion were specific to each outcome and utilised any available data collected during period from age 11-16 years. For mental health outcomes (depression, anxiety, and future self harm) participants were excluded if they had ever scored above a cut-off of 11 on the short mood and feelings questionnaire (assessed on four occasions at age 11,13,14, and 16). For substance use outcomes, participants were excluded if they had ever used the respective substances to harmful/significant levels in the past, taking into consideration age related differences in consumption. For educational and occupational outcomes (GCSEs, A levels, and NEET), participants were excluded if they had failed to achieve expected levels of performance in any of the three national curriculum assessments that are taken before GCSEs.

On average across imputed datasets, the proportion with evidence of previous problems was $29.7 \%$ for CIS-R depressive disorder, $29.9 \%$ for CIS-R anxiety disorder, $29.7 \%$ for self harm in past year at age $21,24.4 \%$ for harmful alcohol use, $20.4 \%$ for problem cannabis use, $23.8 \%$ for regular smoking, $21.7 \%$ for illicit drug use, $41.5 \%$ for not achieving five or more GCSEs or equivalent $A^{*}-\mathrm{C}, 41.7 \%$ for not achieving three or more A levels, and $41.7 \%$ for NEET.

The proportion of participants with a history of self harm by age 16 years that were excluded ranged from $33.3 \%$ (for previous problem cannabis use; $31.8 \%$ of those with non-suicidal self harm, and $36.0 \%$ of those with suicidal self harm) to $60.1 \%$ (for history of probable depression; $50.3 \%$ of those with non-suicidal self harm and $77.2 \%$ of those with suicidal self harm).

*Educational and occupational outcomes additionally adjusted for IQ at age 8 years. 


\section{Figure}

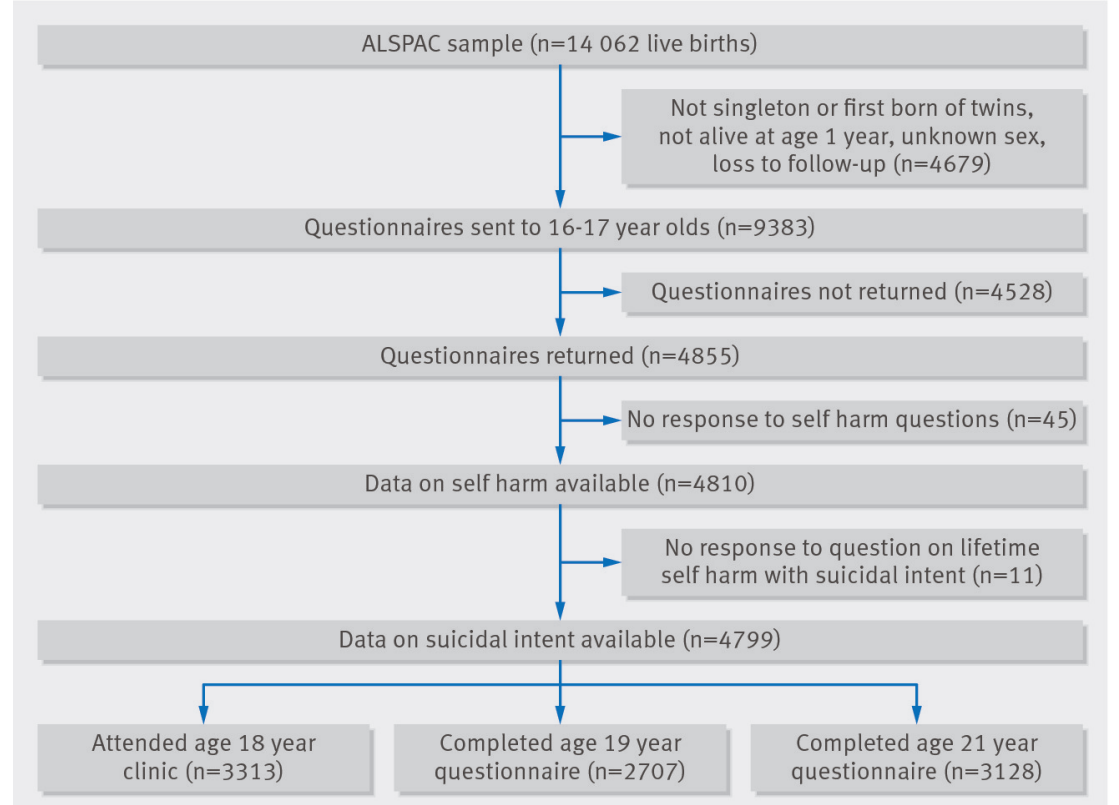

Flowchart of attrition and self harm outcomes in Avon Longitudinal Study of Parents and Children (ALSPAC) birth cohort 